\title{
High-Precision GNSS PWV and Its Variation Characteristics in China Based on Individual Station Meteorological Data
}

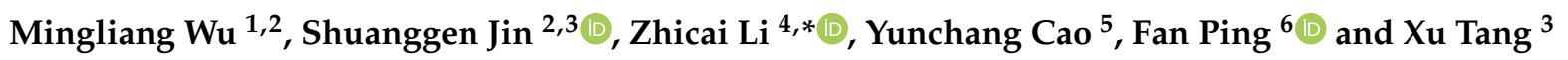 \\ 1 College of Civil Engineering and Mechanics, Xiangtan University, Xiangtan 411105, China; \\ wumingliang@shao.ac.cn \\ 2 Shanghai Astronomical Observatory, Chinese Academy of Sciences, Shanghai 200030, China; sgjin@shao.ac.cn \\ 3 School of Remote Sensing and Geomatics Engineering, Nanjing University of Information Science and \\ Technology, Nanjing 210044, China; xu.tang@nuist.edu.cn \\ 4 Department of Geodesy, National Geomatics Center of China, Beijing 100830, China \\ 5 Center for Meteorological Exploration, China Meteorological Administration, Beijing 100081, China; \\ caoyc@nsmc.cma.gov.cn \\ 6 Institute of Atmospheric Physics, Chinese Academy of Sciences, Beijing 100029, China; pingf@mail.iap.ac.cn \\ * Correspondence: zcli@ngcc.cn; Tel.: +86-10-63881436
}

Citation: Wu, M.; Jin, S.; Li, Z.; Cao, Y.; Ping, F.; Tang, X. High-Precision GNSS PWV and Its Variation Characteristics in China Based on Individual Station Meteorological Data. Remote Sens. 2021, 13, 1296. https://doi.org/10.3390/rs13071296

Academic Editor: Stefania Bonafoni

Received: 24 February 2021

Accepted: 25 March 2021

Published: 29 March 2021

Publisher's Note: MDPI stays neutral with regard to jurisdictional claims in published maps and institutional affiliations.

Copyright: () 2021 by the authors. Licensee MDPI, Basel, Switzerland. This article is an open access article distributed under the terms and conditions of the Creative Commons Attribution (CC BY) license (https:// creativecommons.org/licenses/by/ $4.0 /)$.

\begin{abstract}
The Global Navigation Satellite System (GNSS) plays an important role in retrieving high temporal-spatial resolution precipitable water vapor (PWV) and its applications. The weighted mean temperature $\left(T_{m}\right)$ is a key parameter for the GNSS PWV estimation, which acts as the conversion factor from the zenith wet delay (ZWD) to the PWV. The $T_{m}$ is determined by the air pressure and water vapor pressure, while it is not available nearby most GNSS stations. The empirical formular is often applied for the GNSS station surface temperature $\left(T_{S}\right)$ but has a lower accuracy. In this paper, the temporal and spatial distribution characteristics of the coefficients of the linear $T_{m}-T_{s}$ model are analyzed, and then a piecewise-linear $T_{m}-T_{S}$ relationship is established for each GPS station using radiosonde data collected from 2011 to 2019 . The $T_{m}$ accuracy was increased by more than $10 \%$ and $20 \%$ for 86 and 52 radiosonde stations, respectively. The PWV time series at 377 GNSS stations from the infrastructure construction of national geodetic datum modernization and Crustal Movement Observation Network of China (CMONC) were further obtained from the GPS observations and meteorological data from 2011 to 2019. The PWV accuracy was improved when compared with the Bevis model. Furthermore, the daily and monthly average values, long-term trend, and its change characteristics of the PWV were analyzed using the high-precision inversion model. The results showed that the averaged PWV was higher in Central-Eastern China and Southern China and lower in Northwest China, Northeast China, and North China. The PWV is increasing in most parts of China, while the some PWVs in North China show a downward trend.
\end{abstract}

Keywords: GPS meteorology; weighted mean temperature; precipitable water vapor; radiosonde

\section{Introduction}

Water vapor is an important part of the Earth's hydrosphere and plays a key role in the energy exchange and water cycle in nature. The atmospheric water vapor content is limited by local temperature and pressure and is closely related to the formation of various precipitation, such as clouds, rain, and snow [1]. Accurate measurements of water vapor and its distribution changes have become one of the basic problems in synoptics, weather forecasting, and climate research [2-5]. One of the indicators to measure the amount of atmospheric water vapor is the precipitable water vapor (PWV), which represents a certain height of the water column produced by the condensation of all tropospheric atmospheric water vapor in the column per unit bottom area at any time into liquid water. Since the demand for real-time and accurate weather services is becoming more and more urgent, the traditional detection technologies such as radiosondes, water vapor radiometers, and 
solar photometers cannot meet the application requirements for continuous high-precision, high-temporal resolution monitoring of water vapor.

Nowadays, Global Navigation Satellite System (GNSS) technology has become an important means to obtain precipitable water vapor with high temporal and spatial resolution, and many scholars have used GNSS technology to study global or regional climate change and characteristics [6-12]. Bevis et al. first proposed the concept of GPS meteorology and obtained the global surface temperature and weighted mean temperature from 8718 radiosonde stations in North America and explained the linear relationship coefficient and specific process of ground-based GPS inversion of water vapor [13]. Ross and Rosenfeld used 23 years of profile data from 53 radiosonde stations from the National Center for Atmospheric Research to calculate the global $T_{m}-T_{s}$ linear coefficient and demonstrated that it was related to the station and the season except the equatorial region [14]. Several $T_{m}-T_{s}$ conversion models were established for different regions and different seasons using limited meteorological observation data [15-18]. Yao et al. established the nonlinear transformation relationship by combining mathematical statistics and derivation, which can improve the accuracy of fitting in China [19]. However, many GPS stations are not equipped with temperature and pressure sensors due to cost and other reasons. Hence, it is impossible to use transformation coefficient from real observations to calculate $T_{m}$.

Many researchers used the National Centers for Environmental Prediction (NCEP), and the European Center for Medium-term Weather Prediction (ECMWF) reanalyzed data and interpolated data from the ground meteorological observation station to obtain ground temperature and air pressure for ground-based GNSS PWV inversion [20-25]. Yao et al. established a global $T_{m}$ model and a tropospheric delay model using spherical harmonic functions with considering annual, semi-annual, and diurnal changes, which greatly improved the accuracy of the PWV estimation [26,27]. However, the empirical models have relatively low accuracy. The research on $T_{m}-T_{s}$ models in the region of China was mostly focused on climate zones and seasonal divisions. Since many GPS stations in China lacked meteorological data in the past, they cannot obtain precise PWV, as well as investigate their long-term variation characteristics of GPS PWV.

In this study, we collected more radiosonde stations observations at co-located GNSS stations from the infrastructure construction of national geodetic datum modernization and Crustal Movement Observation Network of China (CMONC). The temporal and spatial distribution characteristics of the $T_{m}-T_{s}$ model were analyzed from radiosonde data, and a piecewise-linear model was established at each radiosonde station in China. With this model, the nine-year GPS PWV time series at GNSS stations was obtained from CMONC GNSS observations and meteorological data. The precision of the PWV was evaluated, and the distribution characteristics and their changes were investigated. Section 2 shows the data and methods, evaluation and comparison are presented in Section 3, variations in the characteristics of GNSS PWV are presented in Section 4, and finally, the conclusions are given in Section 5 .

\section{Data and Methods}

\subsection{Observation Data}

The infrastructure construction of national geodetic datum modernization in China was launched in 2012 and completed in 2017, which contained 210 GPS stations. A highprecision, dynamic, and unified modern surveying and mapping datum system was established to provide coordinate frame services, including data products, real-time positioning, processing and analysis, and other services [28]. Crustal Movement Observation Network of China (CMONC) was established in 2006 and completed in 2012, which contained 360 GPS stations [29,30]. The National Geomatics Center of China (NGCC) provided the hourly ZTD data and 1-h measured temperature and atmospheric pressure data at these GPS stations from 2011 to 2019. We used BERNESE 5.2 software [31] to process the raw data, including the implementation of daily solutions and adjustments [32]. 
The Integrated Global Radiosonde Archive (IGRA) has released radiosonde and pilot balloon observations with more than 2700 stations around the world since 1905, including air pressure, temperature, geopotential height, and relative humidity (ftp: / / ftp.ncdc.noaa. gov / pub/data/igra, accessed on 24 January 2021), whose temporal resolution is $12 \mathrm{~h}$. We used IGRA-released radiosonde profiles in China from 2011 to 2019 to calculate the $T_{m}$ at each radiosonde station. Figure 1 shows all the used GPS stations and radiosonde stations.

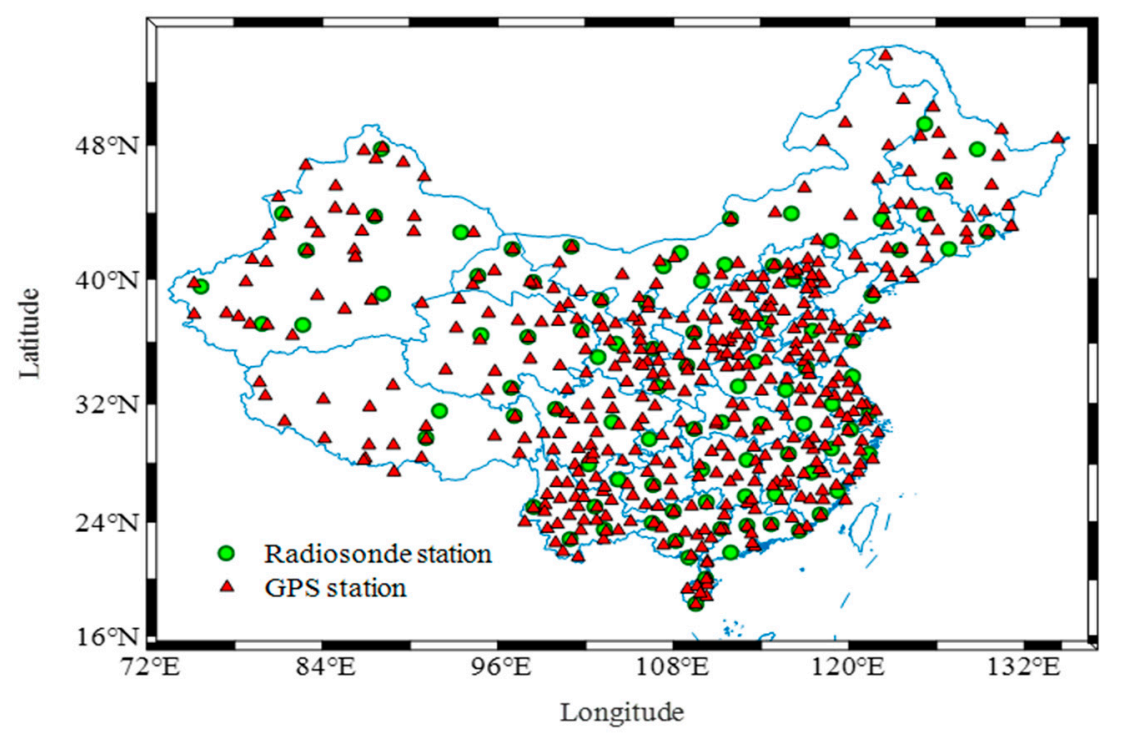

Figure 1. Distribution of GPS stations from the infrastructure construction of national geodetic datum modernization and Crustal Movement Observation Network of China (CMONC) in mainland China. The green circle is the radiosonde station, and the red triangle is the GPS station.

\subsection{Establishment of Site-Specific Piecewise-Linear $T_{m}-T_{s}$ Relationship}

$T_{m}$ is related to the temperature and vapor pressure at different altitudes in the atmosphere, which can be obtained from the IGRA. The method to calculating the 12-h $T_{m}$ can be expressed as [13]:

$$
T_{m}=\frac{\int_{z_{0}}^{+\infty}\left(\frac{e}{T}\right) d z}{\int_{z_{0}}^{+\infty}\left(\frac{e}{T^{2}}\right) d z} \approx \frac{\sum_{i=1}^{N}\left(\frac{e_{i}}{T_{i}}\right) \Delta z_{i}}{\sum_{i=1}^{N}\left(\frac{e_{i}}{T_{i}^{2}}\right) \Delta z_{i}}
$$

where $e(\mathrm{hPa})$ refers to the water vapor pressure, $T(\mathrm{~K})$ is the corresponding temperature, and $Z(\mathrm{~m})$ denotes the starting height of integration. $\Delta z_{i}(\mathrm{~m})$ denotes the altitude of the $i$ th atmospheric layer, $N$ denotes the number of the atmospheric layer, $e_{i}(\mathrm{hPa})$ denotes the water vapor pressure of $i$ th atmospheric layer, and $T_{i}(\mathrm{~K})$ denotes the temperature of $i$ th atmospheric layer. We converted the geopotential height into the geoid height in the calculation process.

The empirical formula based on the long-term radiosonde data in the study area and the linear relationship between surface temperature $T_{s}$ and $T_{m}$ can be established by a regression analysis as:

$$
T_{m}=a \cdot T_{s}+b
$$

where $a$ and $b$ are the linear regression equation parameters.

The $T_{m}$ variation has a significant annual variation. In some studies, the half-year variations and the daily variations are also considered when building the model. In order to get the time-varying characteristics of the $T_{m}-T_{s}$ coefficient, a piecewise-linear least squares fitting is performed for each radiosonde station for one month. 


\subsection{PWV from Site-Specific Piecewise-Linear $T_{m}-T_{s}$ Relationship}

Three hundred and seventy-seven GPS stations were selected for estimating the PWV time series. Since the cubic spline method has a higher accuracy than the nearest-neighbor interpolation method and linear interpolation method, we used the cubic spline method to obtain the $T_{m}-T_{S}$ model coefficients $a$ and $b$ at the GPS stations in the corresponding time period.

ZTD is the sum of Zenith Hydrostatic Delay (ZHD) and Zenith Wet Delay (ZWD), as

$$
\mathrm{ZTD}=\mathrm{ZHD}+\mathrm{ZWD}
$$

The Saastamoinent model has been widely used for ZHD computation [33], as

$$
\mathrm{ZHD}=0.002277 \cdot \frac{P}{1-0.0026 \cdot \cos (2 \phi)-0.00028 \cdot h_{0}}
$$

where $P(\mathrm{hPa})$ denotes the ground pressure of the GPS station, $\phi$ denotes the latitude of the GPS station, and $h_{0}(\mathrm{~m})$ denotes the elevation of the GPS station.

The ZWD is caused by water vapor in the atmosphere under nonstatic equilibrium. Generally, empirical models and meteorological parameters at GPS station are used to obtain the ZHD, and then, the ZHD is deducted from the ZTD to obtain the ZWD.

$$
\mathrm{ZWD}=\mathrm{ZTD}-\mathrm{ZHD}
$$

The linear relationship between the ZWD and PWV can be expressed as [13]

$$
\begin{gathered}
\text { PWV }=\Pi \cdot Z W D \\
\Pi=\frac{10^{6}}{\rho_{w} \cdot \frac{R}{m_{w}} \cdot\left[\frac{k_{3}}{T_{m}}+k_{2}-\frac{m_{w}}{m_{d}} \cdot k_{1}\right]}
\end{gathered}
$$

where $\Pi$ is the conversion factors between the ZWD and PWV; $\Pi$ is a function of $T_{m}$; $\rho_{w}$ represents the density of the liquid water; $R$ is the universal gas constant and $R=8314$ $\mathrm{Pa} \cdot \mathrm{m}^{3} \cdot \mathrm{K}^{-1} \cdot \mathrm{kmol}^{-1} ; m_{w}$ represents the molar mass of water vapor and $m_{w}=18.02 \mathrm{~kg} \cdot \mathrm{kmol}^{-1}$; $m_{d}$ represents the molar mass of the dry atmosphere and $m_{d}=28.96 \mathrm{~kg} \cdot \mathrm{kmol}^{-1}$; and $k_{1}, k_{2}$, and $k_{3}$ are constants $\left(k_{1}=77.604 \pm 0.014 \mathrm{~K} / \mathrm{hPa}, k_{2}=70.4 \mathrm{~K} / \mathrm{hPa}\right.$, and $k_{3}=(3.776 \pm 0.014)$ $\times 10^{5} \mathrm{~K}^{2} / \mathrm{hPa}$ ) [13].

In general, approximately $6.7 \mathrm{~mm}$ of ZTD error will cause a PWV error of $1 \mathrm{~mm}$. Hence, the ZTD with a Root Mean Square Error (RMSE) of greater than $6.7 \mathrm{~mm}$ are eliminated. In addition, ZTD data and meteorological parameters are missing at some stations in a few time periods. For sites with missing data for more than one year, they will not be used when analyzing the long-term changes. Then, Equations (3)-(6) were used for high-precision PWV estimations based on the site-specific piecewise-linear $T_{m}-T_{s}$ relationship in China. Finally, the PWV time series derived from 377 GPS stations in China from 2011 to 2019 were obtained.

\subsection{PWV from Radiosonde}

The PWV at the radiosonde station is calculated as follows:

$$
\mathrm{PWV}=\int_{0}^{p_{0}} \frac{q}{\rho_{w} g} d_{p}
$$

where $p(\mathrm{hPa})$ denotes the atmospheric pressure, $p_{0}(\mathrm{hPa})$ is the ground pressure at the GPS station, $q\left(\mathrm{~g} \cdot \mathrm{kg}^{-1}\right)$ denotes the specific humidity, $g\left(\mathrm{~m} \cdot \mathrm{s}^{-2}\right)$ is the acceleration of gravity, and $\rho_{w}\left(\mathrm{~g} \cdot \mathrm{cm}^{-3}\right)$ refers to the density of the liquid water. By discretizing Equation (8), 
the integral equation of PWV from the ground to the top of the atmosphere is obtained as follows:

$$
\mathrm{PWV}=-\frac{1}{g} \sum_{p_{0}}^{p} q \times p
$$

\subsection{Fitting Function of the PWV Time Series}

Jin and Luo [34] analyzed the PWV series derived from 155 globally distributed GPS sites observations and found that most of the periods of the PWV series were 1 year, 0.5 years, 1 day, and 0.5 days. To fit the PWV time series of 377 GPS stations in China, we established the following equation:

$$
\begin{aligned}
\mathrm{PWV} & =k_{0}+k_{1} \cdot \cos \left(\frac{D O Y-c_{1}}{365.25} \cdot 2 \pi\right)+k_{2} \cdot \cos \left(\frac{D O Y-c_{2}}{365.25} \cdot 4 \pi\right)+k_{3} \cdot \cos \left(\frac{H O D-c_{3}}{24} \cdot 2 \pi\right) \\
& +k_{4} \cdot \cos \left(\frac{H O D-c_{4}}{24} \cdot 4 \pi\right)+\varepsilon
\end{aligned}
$$

where $k_{0}$ is a constant term; $k_{1}, k_{2}, k_{3}, k_{4}, c_{1}, c_{2}, c_{3}$, and $c_{4}$ are the amplitude and phase at the period (1 year, 0.5 years, 1 day, and 0.5 days); DOY is the day of year; HOD is the hour of day; and $\varepsilon$ is the residual. The least square method was used to determine the unknown parameters in Equation (10) with the PWV time series.

\section{Evaluation and Comparison}

\subsection{Spatial Distribution and Time-Varying Characteristics of the $T_{m}-T_{s}$ Coefficient}

Figure 2 shows the spatial distribution of the $T_{m}-T_{s}$ relationship coefficients. The slope coefficient ranges from 0.5 to 0.7 in South China, around 0.7 in Northwest China, and about 0.8 in Central and Northeast China. As shown in the right panel, the intercept coefficient is from 80 to 140 in Southern China, about 60 in Central and Northwestern China, and approximately 20 in Northeastern China.

(a) slope coefficient a

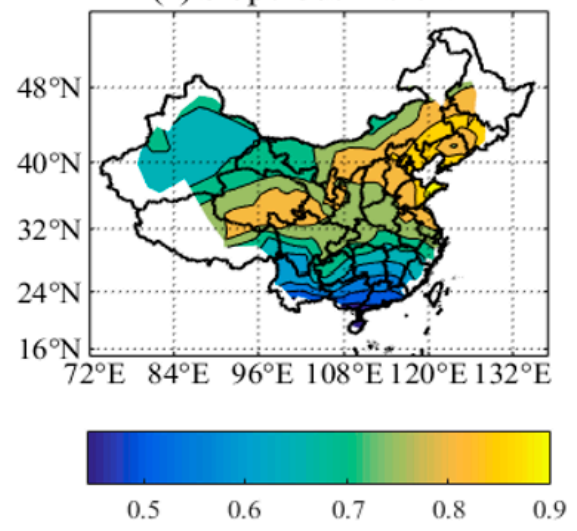

(b) intercept coefficient b (K)

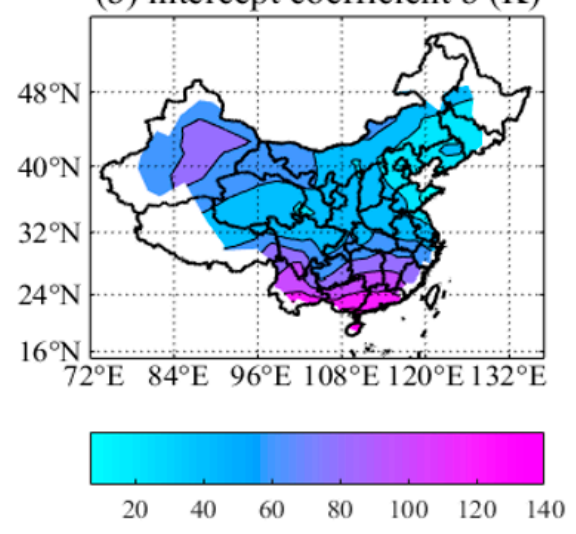

Figure 2. Distribution of the $T_{m}-T_{s}$ fitting coefficients a and $\mathrm{b}$ at each station by $T_{m}=a * T_{s}+b$. (a) The slope coefficient $a$ and (b) the intercept coefficient $b$.

Figure 3 shows the distribution diagram of the slope coefficient with the elevation, latitude, and longitude. No evident correlation is found with the elevation and longitude, whereas there is strong positive correlation with the latitude, especially in low-latitude areas. Some studies have shown that when the same $T_{m}-T_{S}$ coefficient is used at a global scale, it will cause different errors in the $T_{m}$ of different latitudes [35,36]. Wang et al. found that the $T_{m}$ derived from the Bevis $T_{m}-T_{s}$ relationship has a cold bias in the tropics and subtropics and a warm bias in middle and high latitudes, and furthermore, the RMS was dominated by the mean bias rather than the random error. Therefore, the distribution of the $T_{m}-T_{s}$ coefficients is mostly related to the latitude. The slope coefficient $a$ is generally 
less than 0.6 in low-latitude areas, which is consistent with the previous results of some global $T_{m}-T_{s}$ models.
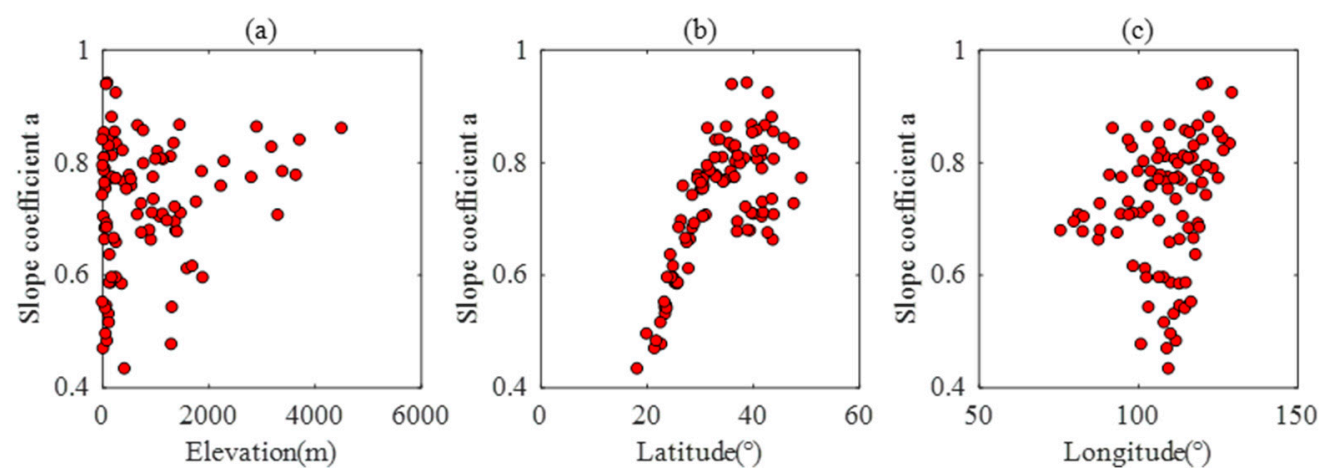

Figure 3. Distribution of the $T_{m}-T_{s}$ model slope coefficient with the elevation (a), latitude (b), and longitude (c).

The monthly coefficients of the $T_{m}-T_{s}$ model are obtained. The slope coefficients have obvious annual cycle at most stations. The time series of slope coefficients at four radiosonde stations are randomly selected and shown in Figure 4. The information of the four stations is shown in Table 1 . The slope coefficients of the $T_{m}-T_{S}$ model vary greatly with the time, from about $0.5-1$. The regression slope and its changing tendency are smaller at the SIMAO station, which is due to the lower latitude.

(a) 50774

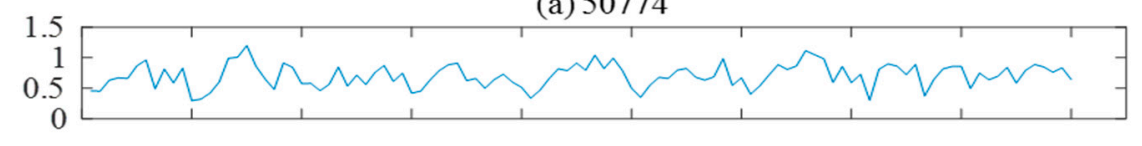

(b) 50953

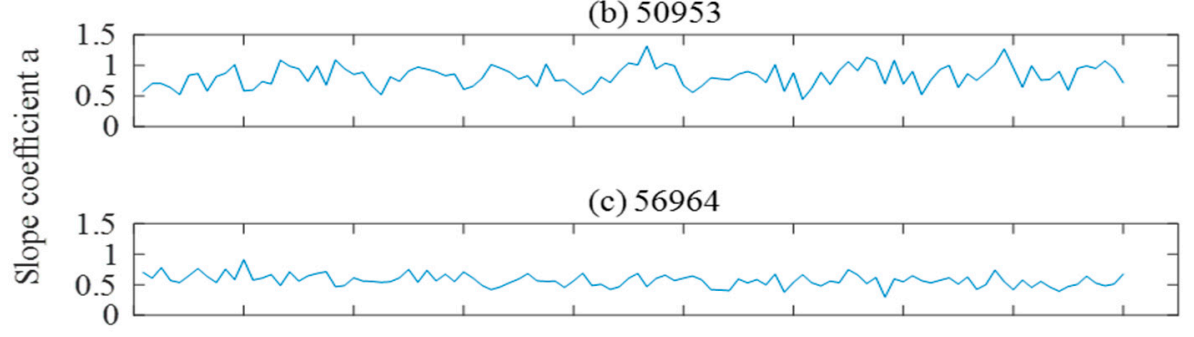

(d) 58424

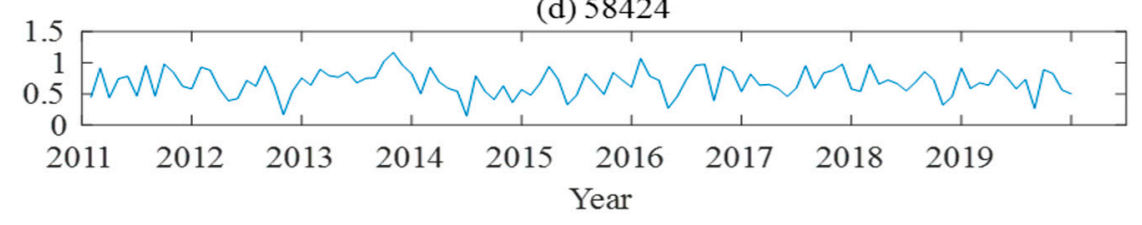

Figure 4. Monthly slope coefficient of the $T_{m}-T_{S}$ model from 2011 to 2019.

Table 1. Information about the 4 stations used in Figure 4 .

\begin{tabular}{ccccc}
\hline Name & Number & $\begin{array}{c}\text { Latitude } \\
\left(\mathbf{(}^{\circ}\right.\end{array}$ & $\begin{array}{c}\text { Longitude } \\
\left({ }^{\circ}\right)\end{array}$ & Height (m) \\
\hline YICHUN & 50,774 & 47.72 & 128.83 & 264.8 \\
HARBIN & 50,953 & 45.93 & 126.57 & 118.3 \\
SIMAO & 56,964 & 22.77 & 100.98 & 1303.0 \\
ANQING & 58,424 & 30.62 & 116.97 & 62.0 \\
\hline
\end{tabular}




\subsection{Comparison with Bevis $T_{m}-T_{s}$ Relationship}

We calculated the root mean square error (RMSE) (in unit of K) and accuracy improvement (\%) of $T_{m}$ for 94 radiosonde station, which are shown in Figure 5. Compared with the Bevis model, the site-specific piecewise-linear model has a significant improvement in the regression accuracy at most stations due to the consideration of the temporal and spatial distributions of the $T_{m}-T_{s}$ conversion coefficient. According to the statistics, the $T_{m}$ accuracy with 86 radiosonde stations is increased by more than $10 \%$ and by more than $20 \%$ with 52 radiosonde stations, and the lowest is increased by $6 \%$ (station $58457,30.23^{\circ} \mathrm{N}$, $120.17^{\circ} \mathrm{E}$ ), and the highest is increased by $69^{\%}$ (station $56691,26.87^{\circ} \mathrm{N}, 104.28^{\circ} \mathrm{E}$ ).

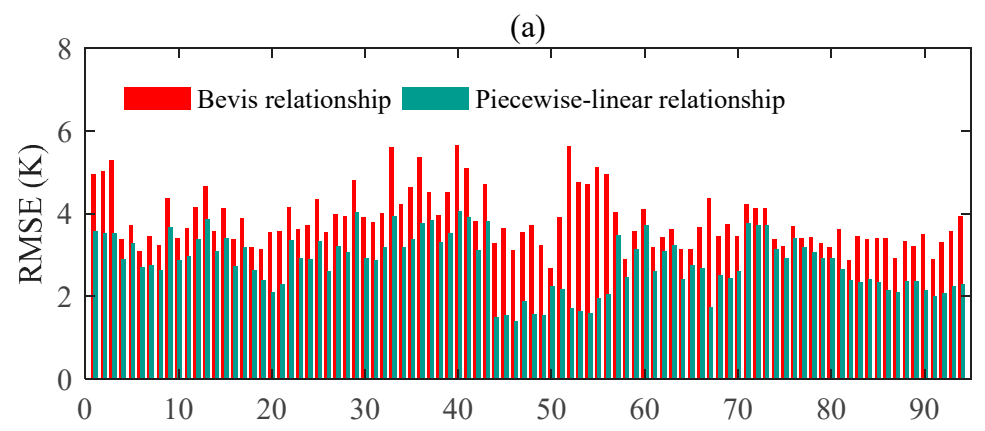

(b)

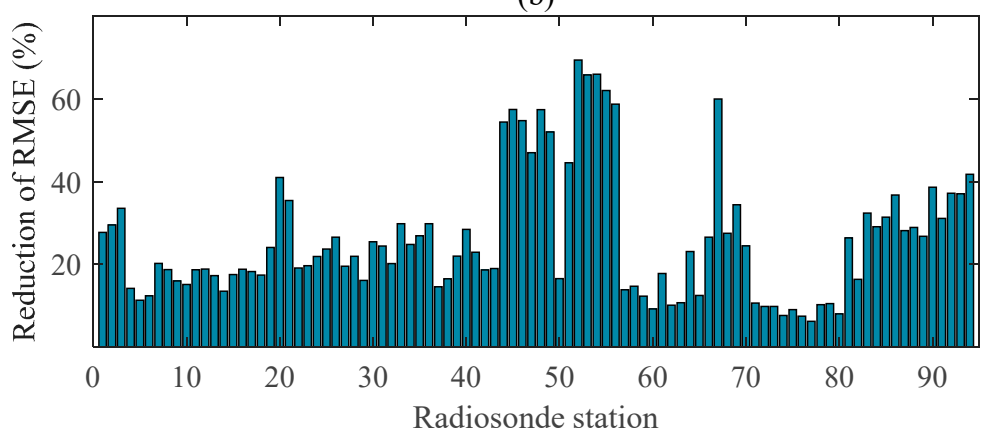

Figure 5. RMSE (K) (a) and accuracy improvement of the $T_{m}(\mathbf{b})$ calculated by the site-specific piecewise-linear and Bevis $T_{m}-T_{S}$ relationship.

Figure 6 shows the RMSE distribution of the Bevis model and the site-specific piecewiselinear model. As we can see, compared with the Bevis model, the single-station piecewiselinear model has a greater accuracy improvement in the southern, southwest, and northeastern regions by more than $30 \%$. The increase in the central and northwestern regions is relatively small and approximately $15 \%$.

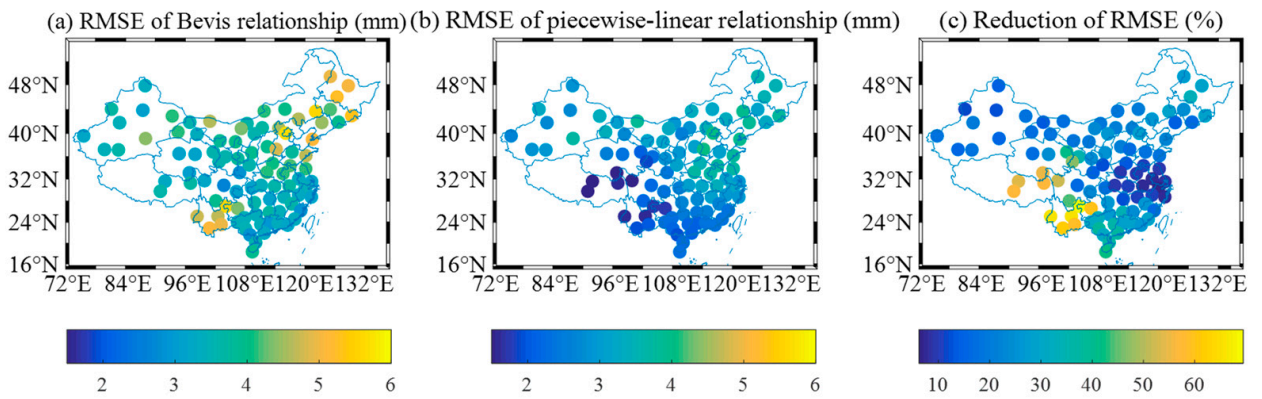

Figure 6. RMSE (K) distribution of the $T_{m}$ calculated by the site-specific piecewise-linear relationship (a), Bevis $T_{m}-T_{S}$ relationship (b), and reduction of the RMSE (\%) by the site-specific piecewise-linear $T_{m}-T_{s}$ relationship (c). 


\subsection{Comparison with GPS-Derived PWV and Radiosonde PWV}

The selected GPS stations are closer to the radiosonde, in which the horizontal distance is less than $10 \mathrm{~km}$ and the elevation difference is less than $100 \mathrm{~m}$. The water vapor obtained by the integral of the radiosonde profile data was used to evaluate the ground-based GPS PWV based on the Bevis model and the site-specific piecewise-linear $T_{m}-T_{s}$ model. We calculated the deviation bias (in unit of $\mathrm{mm}$ ) and relative errors. For example, Figure 7 shows the results at GXHC station in 2018. The accuracy of the PWV is better based on the site-specific piecewise-linear $T_{m}-T_{s}$ relationship when compared to the Bevis's model.

(a)

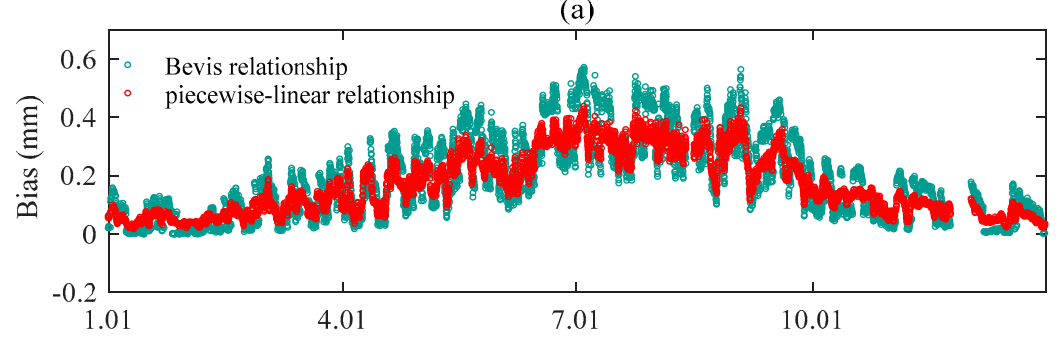

(b)

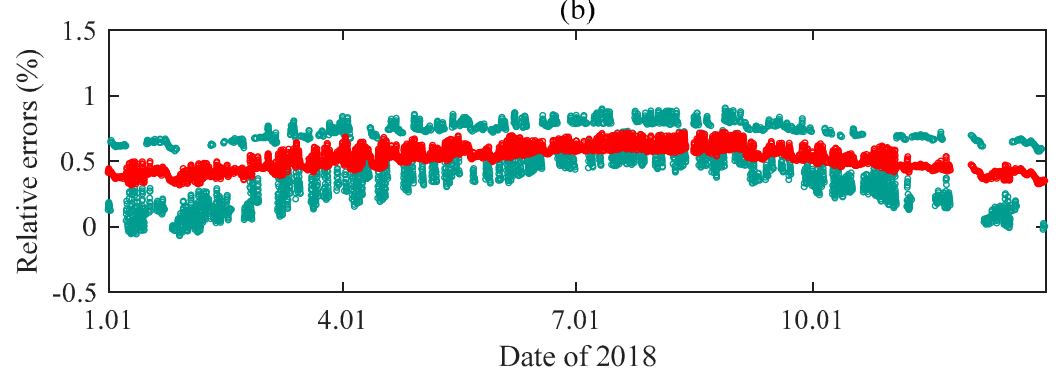

Figure 7. Bias (mm) (a) and relative error (\%) (b) of the precipitable water vapor (PWV) calculated based on different $T_{m}-T_{s}$ models at GXHC station in 2018. The blue dots are the PWV based on the Bevis model, and the red dots are the PWV based on the site-specific piecewise-linear model.

The distribution of water vapor in the atmosphere is not uniform. Thus, the groundbased GPS water vapor can get the average distribution of water vapor in each satellite signal direction. In addition, the layered meteorological parameter data of the radiosonde is not strictly vertical. These factors will bring errors into the PWV results. However, it still can be seen that the accuracy of the PWV is significantly improved based on site-specific piecewise-linear $T_{m}-T_{s}$ relationship, especially when there are more atmospheric water vapors in the summer.

\section{Variations Characteristics of GNSS PWV}

\subsection{Spatial Distribution of PWV in China}

The annual averaged PWV at all GPS stations from 2011 to 2019 in China range from 0 to $48 \mathrm{~mm}$. As shown in Figure 8, the annual averaged PWV in Central-Eastern China and Southern China are relatively high, reaching above $25 \mathrm{~mm}$, while the annual averaged PWV in Northwest, Northeast, and Northern China regions are lower, below $15 \mathrm{~mm}$. Southeast China has a low latitude and is close to the East China Sea and the South China Sea, which are subject to subtropical monsoons. Monsoons transport water vapor from the sea to these areas, resulting in the higher annual averaged PWV [37]. Northwest China has a relatively high latitude and is an inland region with a temperate continental climate, so the annual averaged PWV is lower.

The GPS stations are divided into four regions: the eastern central region $\left(24.5^{\circ}-37^{\circ} \mathrm{N}\right.$, $\left.105^{\circ}-123^{\circ} \mathrm{E}\right)$, the southern region $\left(19^{\circ}-24.5^{\circ} \mathrm{N}, 105^{\circ}-120^{\circ} \mathrm{E}\right)$, the northwestern region $\left(42^{\circ}-49^{\circ} \mathrm{N}, 80^{\circ}-90^{\circ} \mathrm{E}\right)$, and the northeastern region $\left(37^{\circ}-50^{\circ} \mathrm{N}, 110^{\circ}-130^{\circ} \mathrm{E}\right)$. Figure 9 shows the nine-year daily averaged PWV of these four regions. The variation characteristics of the PWV in each region are consistent throughout the year, with the peaks in June and 
July and the droughts in January and December. Among them, the peak in Southern China appeared the earliest, which was affected by the south-to-north monsoon. Atmospheric circulation transported the water vapor to the Yangtze River Basin and then continued to transport it to other regions [38].

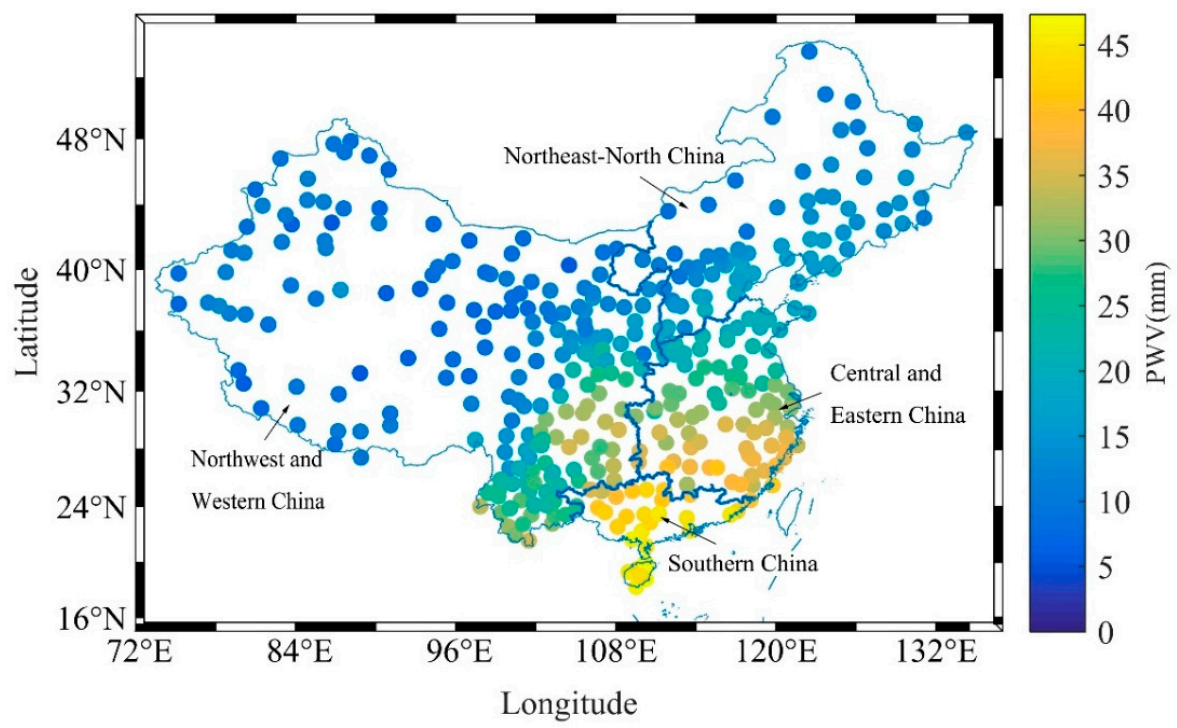

Figure 8. Annual averaged PWV (mm) in China from 2011 to 2019.

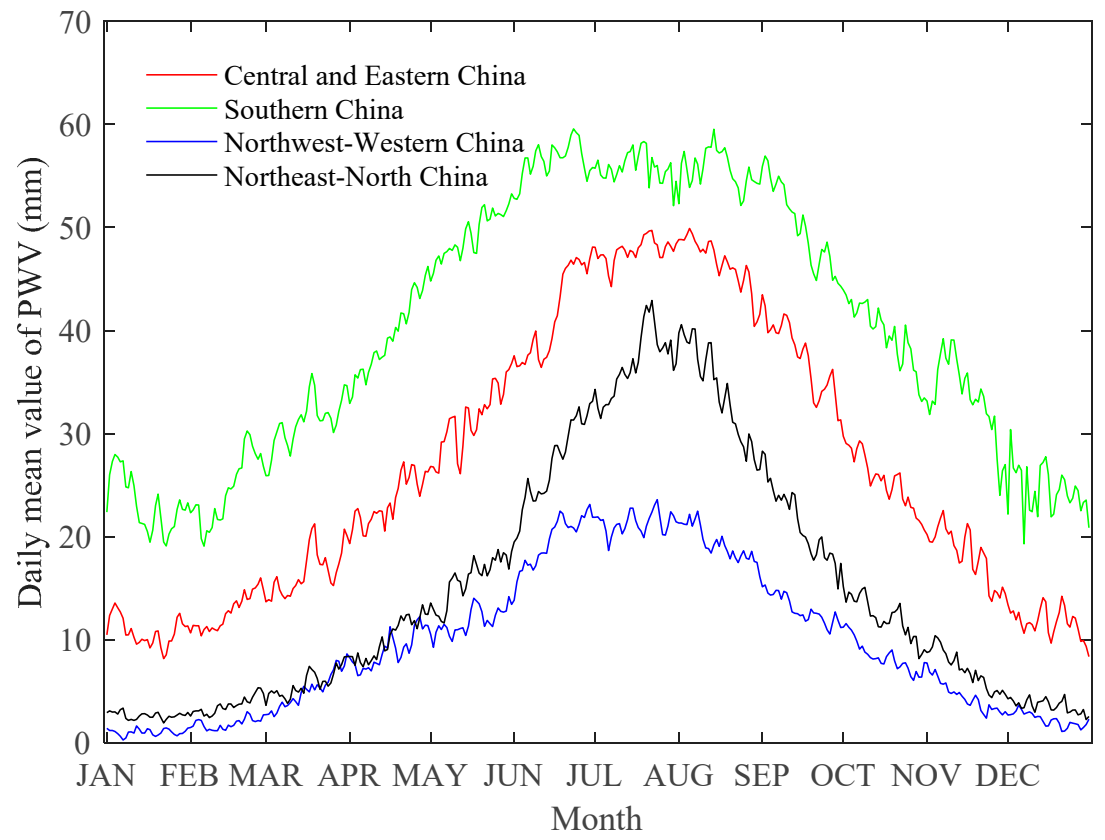

Figure 9. Nine-year averaged daily PWV (mm) in four regions of China from 2011 to 2019.

\subsection{Seasonal Variations of PWV in China}

Figures 10 and 11 show the annual and semiannual PWV variation amplitudes at 377 GPS sites. The spatial distribution of the annual PWV variations is similar to the annual average distribution of the PWV. Central China, Southern China, and the southeast coastal areas have higher annual PWV variation amplitudes, reaching about $15 \mathrm{~mm}$, while the annual cycle amplitude in Northwest China is lower, below $10 \mathrm{~mm}$. The semiannual PWV variation amplitudes are relatively small, about 3-9 $\mathrm{mm}$. Among them, the semiannual PWV variation amplitudes are the highest in Central China and Southwest China, reaching 
above $6 \mathrm{~mm}$, while the semiannual PWV variation amplitudes in Southern China and Northwestern China are lower, below $5 \mathrm{~mm}$.

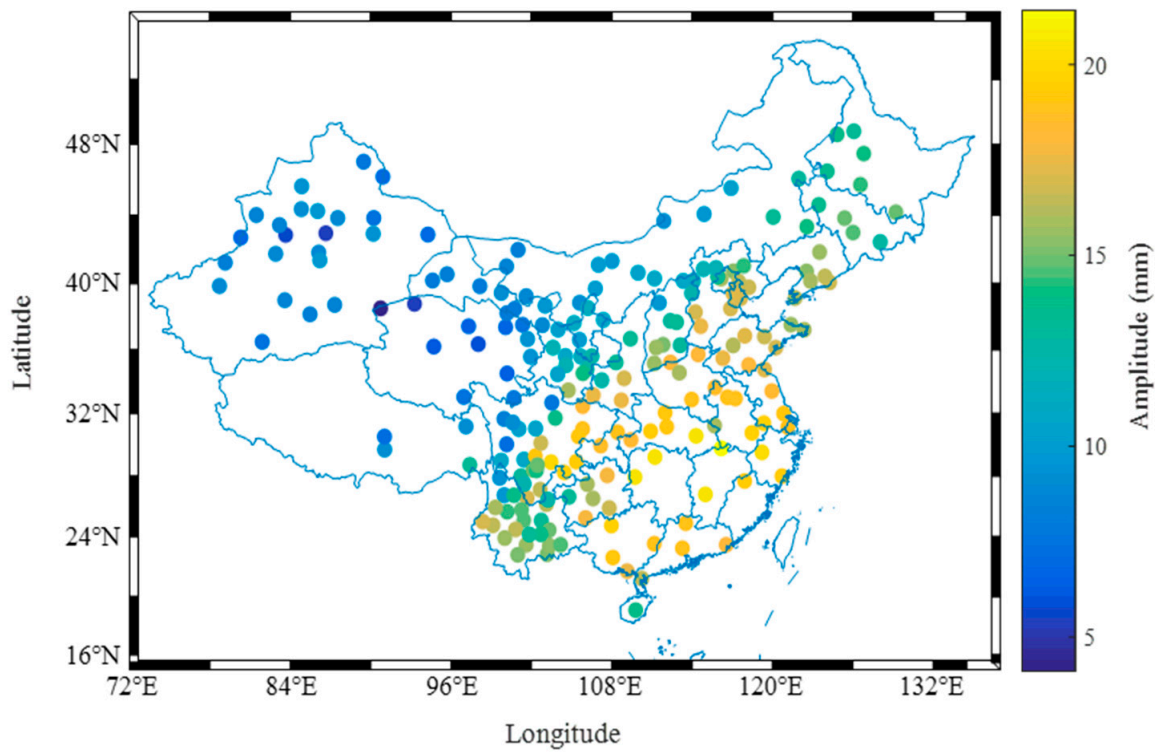

Figure 10. Annual PWV variation amplitudes (mm) at 377 GPS sites.

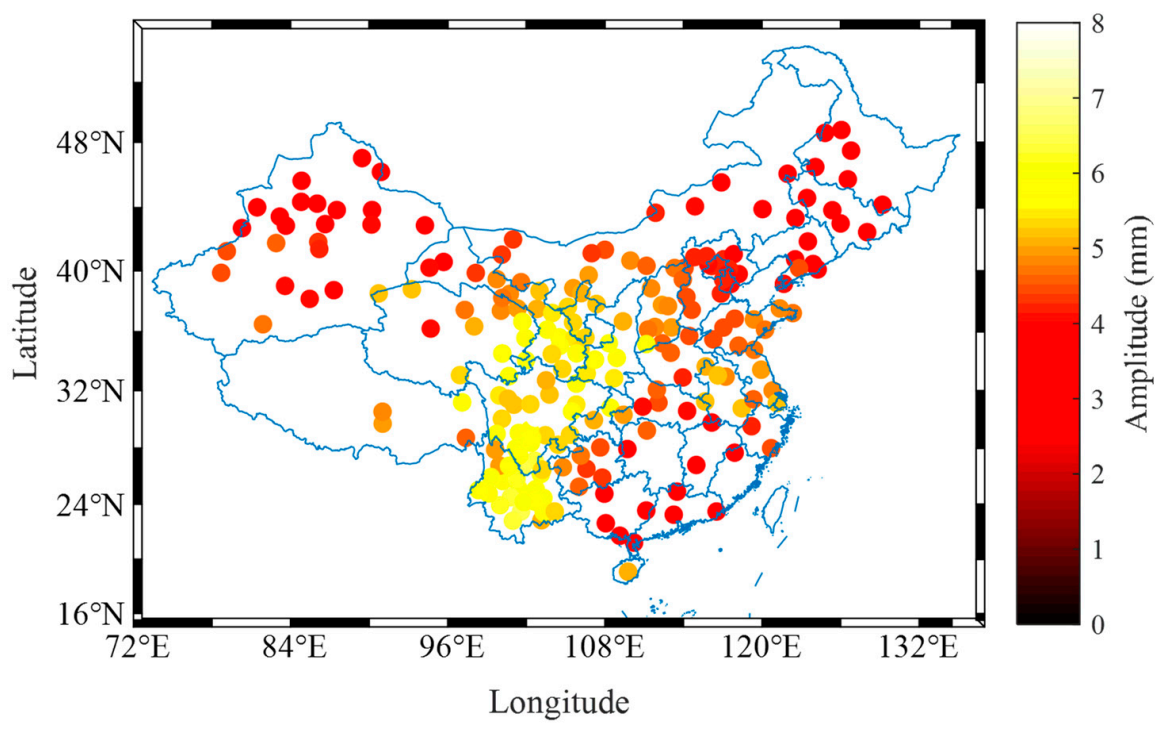

Figure 11. Semiannual PWV variation amplitudes (mm) at 377 GPS sites.

\subsection{Long-Term Variation Trend of PWV in China}

Figure 12 shows the long-term variation trends of the PWV (mm/year) of all GPS stations from 2011 to 2019. It can be seen that the PWV has been increasing in most parts of China, while the PWV in Northeast China shows a downward trend. To understand the variations of the PWV in more detail, a monthly anomaly of the PWV is obtained by subtracting the monthly averaged PWV of every month from the mean value of the monthly averaged nine-year PWV in each region, which can be seen in Figure 13. The monthly anomaly of the PWV was mainly negative before 2015 and then turned negative. The PWV in Northwest China, Northeast China, and Northern China were relatively stable, and the monthly mean value changed little, which was related to the dry inland climate. 

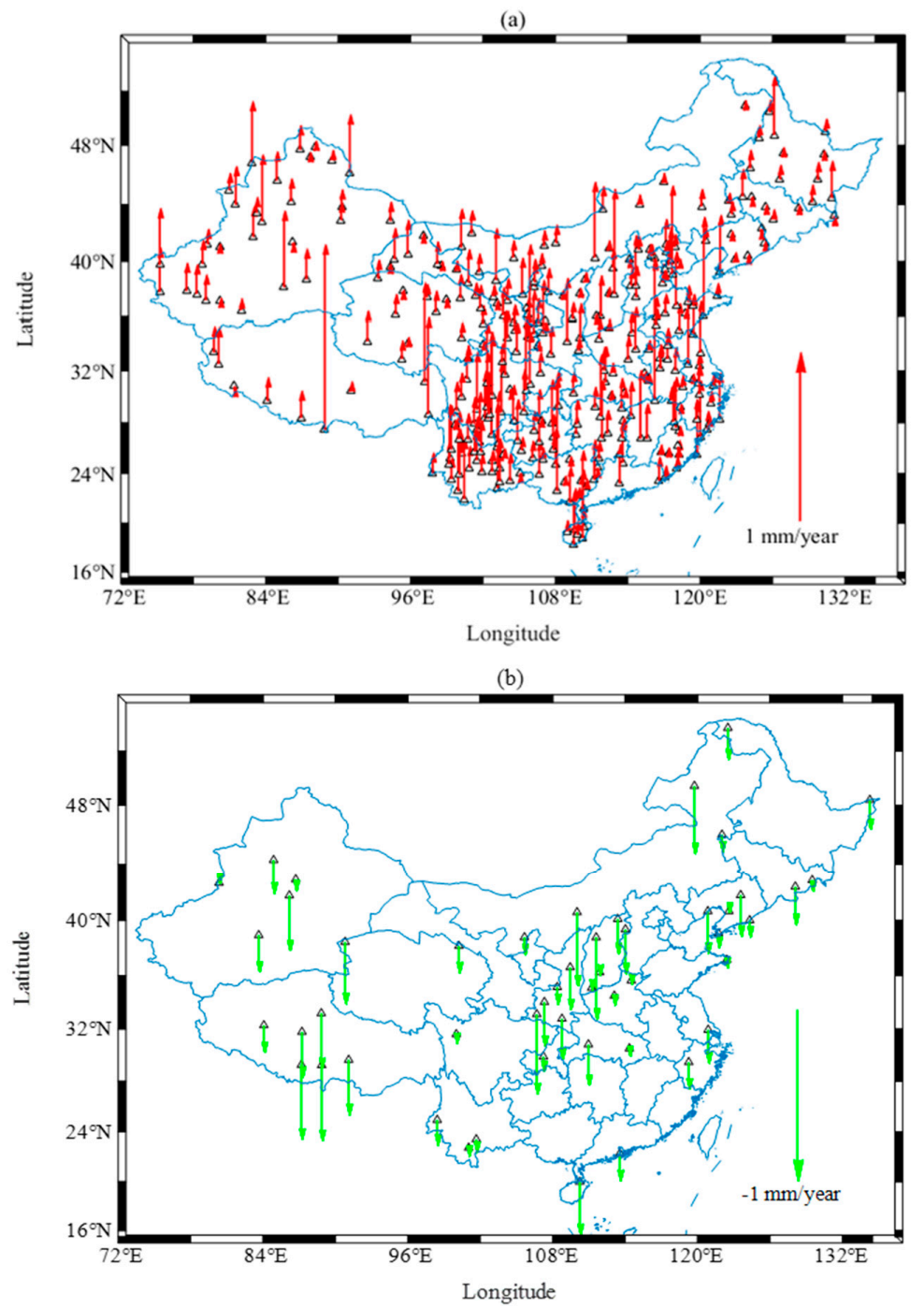

Figure 12. Long-term variation trend of the PWV. The red upward arrows (a) stand for the increase of the PWV variation trend (mm/year), and the green downward arrows (b) represent the decrease of the PWV variation trend ( $\mathrm{mm} /$ year).

(a)

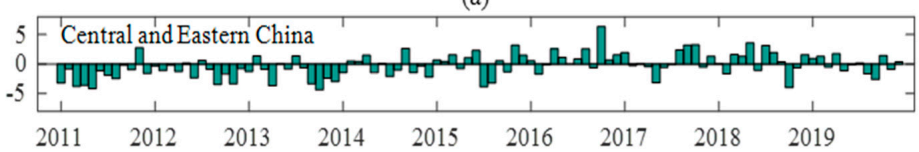

(b)

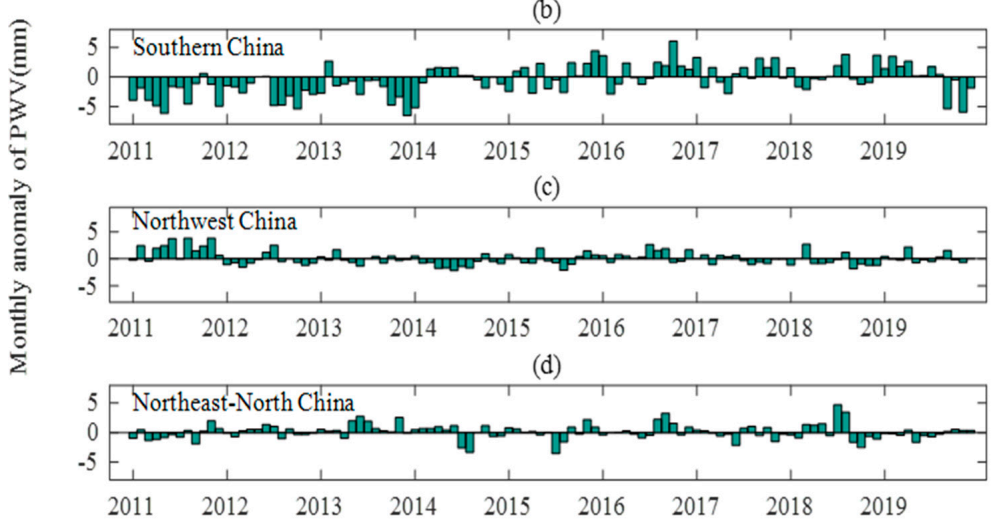

Figure 13. Monthly anomaly ( $\mathrm{mm})$ of the PWV in four regions of China. 


\section{Discussion}

Most of the published $T_{m}$ models that considered the temporal and spatial distributions of the relationship between the $T_{m}$ and meteorological measurements have been empirical models on a global scale. Their accuracy remains to be verified in a specific area and a period of time. Here, we estimated the monthly coefficients at each station, and Table 2 shows the comparison between the piecewise-linear model and two recently published representative models: the time-varying global-gridded $T_{s}-T_{m}$ model (TVGG) and neural network-based $T_{m}$ model $(\mathrm{NN})$. We tested our model with radiosonde data from 2011 to 2019, and the results showed that our model has the best accuracy.

Table 2. Statistics of the $T_{m}$ estimates for different models.

\begin{tabular}{ccccc}
\hline Statistics & Bevis & TVGG & NN-I & Piecewise Linear \\
\hline Bias (K) & -0.74 & -1.25 & 0.03 & 0.00 \\
RMS (K) & 4.58 & 3.84 & 3.62 & 3.38 \\
\hline
\end{tabular}

The spatial distribution characteristics of the PWV are consistent with other studies in different years $[39,40]$. There are bimodal characteristics of the PWV in Southern China, and the formation mechanism of the bimodal characteristics remains to be further studied. The past results of some studies in China indicated that the PWV showed a downward trend from 1995 to 2012 [41-43], while the trends of this article are upward from 2011 to 2019. Most PWV in Central and Eastern China and Southern China show an upward trend and some PWV in North China is downward from 2011 to 2019. The monthly averaged PWV increased significantly in 2015, which was affected by the El Niño.

\section{Conclusions}

In this study, we analyzed the temporal and spatial distribution characteristics of the coefficients of the linear $T_{m}-T_{s}$ model and showed that the distribution of $T_{m}-T_{s}$ coefficients is mainly related to the latitude. The $T_{m}-T_{s}$ conversion coefficient changes with the time and has an obvious annual cycle. Based on the spatial distribution and time-varying characteristics of the $T_{m}-T_{S}$ coefficients, a site-specific piecewise-linear model was established. Compared with the Bevis model, this model reduced the $T_{m}$ RMS by more than $20 \%$ for the most of the tested radiosondes. The accuracy of GPS PWV is better based on the site-specific piecewise-linear $T_{m}-T_{S}$ relationship when compared to the Bevis model. Furthermore, the PWV time series at 377 GNSS stations were further obtained and analyzed from the GPS observations and meteorological data from 2011 to 2019. The results showed that the average PWV in Central and Eastern China and Southern China is higher, reaching more than $25 \mathrm{~mm}$, while the average value is lower and below $15 \mathrm{~mm}$ in Northwest China, Northeast China, and North China. The PWV is increasing in most parts of China, while some PWV in North China show a downward trend.

Author Contributions: Conceptualization, S.J. and Z.L.; methodology, S.J. and M.W.; software, M.W.; validation, S.J., Z.L. and F.P.; formal analysis, M.W.; investigation, M.W. and S.J.; data curation, Z.L. and S.J.; writing—original draft preparation, M.W. and S.J.; writing—review and editing, F.P., Y.C. and X.T.; visualization, M.W.; supervision, S.J.; project administration, S.J.; and funding acquisition, S.J. and Z.L. All authors have read and agreed to the published version of the manuscript.

Funding: This work was supported by the Strategic Priority Research Program Project of the Chinese Academy of Sciences (Grant No. XDA23040100), National Natural Science Foundation of China (NSFC) Project (Grant No. 12073012), and National Key Research and Development Program of China (No. 2016YFB0501405).

Institutional Review Board Statement: Not applicable.

Informed Consent Statement: Not applicable. 
Data Availability Statement: Radiosonde data are available from the Integrated Global Radiosonde Archive (IGRA) (ftp:/ / ftp.ncdc.noaa.gov/pub/data/igra, accessed on 24 January 2021).

Acknowledgments: The authors are grateful to the infrastructure construction of the national geodetic datum modernization in China and Crustal Movement Observation Network of China (CMONC) for providing the GPS observation data.

Conflicts of Interest: The authors declare no conflict of interest.

\section{References}

1. Philipona, R.; Dürr, B.; Ohmura, A.; Ruckstuhl, C. Anthropogenic greenhouse forcing and strong water vapor feedback increase temperature in Europe. Geophys. Res. Lett. 2005, 32. [CrossRef]

2. Gendt, G.; Dick, G.; Reigber, C.; Tomassini, M.; Liu, Y.; Ramatschi, M. Near real time GPS water vapor monitoring for numerical weather prediction in Germany. J. Meteorol. Soc. Jpn. Ser. II 2004, 82, 361-370. [CrossRef]

3. Boutiouta, S.; Lahcene, A. Preliminary study of GNSS meteorology techniques in Algeria. Int. J. Remote Sens. 2013, 34, 5105-5118. [CrossRef]

4. Sapucci, L.F. Evaluation of modeling water-vapor-weighted mean tropospheric temperature for GNSS-integrated water vapor estimates in Brazil. J. Appl. Meteorol. Climatol. 2014, 53, 715-730. [CrossRef]

5. Ning, T.; Wickert, J.; Deng, Z.; Heise, S.; Dick, G.; Vey, S.; Schöne, T. Homogenized time series of the atmospheric water vapor content obtained from the GNSS reprocessed data. J. Clim. 2016, 29, 2443-2456. [CrossRef]

6. Jin, S.; Su, K. PPP models and performances from single-to quad-frequency BDS observations. Satell. Navig. 2020, 1, 1-13. [CrossRef]

7. Jin, S.; Gao, C.; Li, J. Atmospheric sounding from Fengyun-3C GPS radio occultation observations: First results and validation. Adv. Meteorol. 2019, 1, 1-13. [CrossRef]

8. Jin, S.; Li, Z.; Cho, J. Integrated water vapor field and multiscale variations over China from GPS measurements. J. Appl. Meteorol. Climatol. 2008, 47, 3008-3015. [CrossRef]

9. Jones, J.; Guerova, G.; Douša, J.; Dick, G.; de Haan, S.; Pottiaux, E.; van Malderen, R. Advanced GNSS Tropospheric Products for Monitoring Severe Weather Events and Climate; COST Action ES1206 Final Action Dissemination Report; Springer: Berlin/Heidelberg, Germany, 2019; p. 563.

10. Steiner, A.; Kirchengast, G.; Foelsche, U.; Kornblueh, L.; Manzini, E.; Bengtsson, L. GNSS occultation sounding for climate monitoring. Phys. Chem. Earth Part A Solid Earth Geod. 2001, 26, 113-124. [CrossRef]

11. Smith, T.L.; Benjamin, S.G.; Gutman, S.I.; Sahm, S. Short-range forecast impact from assimilation of GPS-IPW observations into the Rapid Update Cycle. Mon. Weather Rev. 2007, 135, 2914-2930. [CrossRef]

12. Kourtidis, K.; Stathopoulos, S.; Georgoulias, A.; Alexandri, G.; Rapsomanikis, S. A study of the impact of synoptic weather conditions and water vapor on aerosol-cloud relationships over major urban clusters of China. Atmos. Chem. Phys. 2015, 15, 10955-10964. [CrossRef]

13. Bevis, M.; Businger, S.; Herring, T.A.; Rocken, C.; Anthes, R.A.; Ware, R.H. GPS meteorology: Remote sensing of atmospheric water vapor using the Global Positioning System. J. Geophys. Res. Atmos. 1992, 97, 15787-15801. [CrossRef]

14. Ross, R.J.; Rosenfeld, S. Estimating mean weighted temperature of the atmosphere for Global Positioning System applications. J. Geophys. Res. Atmos. 1997, 102, 21719-21730. [CrossRef]

15. Bokoye, A.I. Multisensor analysis of integrated atmospheric water vapor over Canada and Alaska. J. Geophys. Res. Atmos. 2003, 108, 4480. [CrossRef]

16. Emardson, T.R.; Derks, H.J. On the relation between the wet delay and the integrated precipitable water vapour in the European atmosphere. Meteorol. Appl. A J. Forecast. Pract. Appl. Train. Tech. Model. 2000, 7, 61-68. [CrossRef]

17. Wang, J.; Zhang, L.; Dai, A.; Hove, T.V.; Baelen, J.V. A near-global, 2-hourly data set of atmospheric precipitable water from ground-based GPS measurements. J. Geophys. Res. Atmos. 2007, 112, 112. [CrossRef]

18. Zhang, H.P.; Liu, J.N.; Zhu, W.Y.; Huang, C. Remote sensing of PWV using ground-based GPS data in Wuhan region. Prog. Astron. 2005, 23, 169-179.

19. Yao, Y.; Liu, J.; Zhang, B.; He, C. Nonlinear relationships between the surface temperature and the weighted mean temperature. Geomat. Inf. Sci. Wuhan Univ. 2015, 40, 112-116.

20. Jade, S.; Vijayan, M. GPS-based atmospheric precipitable water vapor estimation using meteorological parameters interpolated from NCEP global reanalysis data. J. Geophys. Res. Atmos. 2008, 113. [CrossRef]

21. Means, J.D.; Cayan, D. Precipitable water from GPS Zenith delays using North American regional reanalysis meteorology. J. Atmos. Ocean. Technol. 2013, 30, 485-495. [CrossRef]

22. Zhao, Q.; Yao, Y.; Yao, W.; Zhang, S. GNSS-derived PWV and comparison with radiosonde and ECMWF ERA-Interim data over mainland China. J. Atmos. Sol. Terr. Phys. 2019, 182, 85-92. [CrossRef]

23. Lu, C.; Li, X.; Cheng, J.; Dick, G.; Ge, M.; Wickert, J.; Schuh, H. Real-time tropospheric delay retrieval from multi-GNSS PPP ambiguity resolution: Validation with final troposphere products and a numerical weather model. Remote Sens. 2018, 10, 481. [CrossRef] 
24. Abimbola, O.J.; Falaiye, O.A.; Omojola, J. Estimation of Precipitable Water Vapour in Nigeria Using NIGNET GNSS/GPS, NCEP-DOE Reanalysis II and Surface Meteorological Data. J. Phys. Sci. 2017, 28, 19. [CrossRef]

25. Zhang, H.; Yuan, Y.; Li, W.; Zhang, B.; Sensing, R. A real-time precipitable water vapor monitoring system using the national GNSS network of China: Method and preliminary results. IEEE J. Sel. Top. Appl. Earth Obs. 2019, 12, 1587-1598. [CrossRef]

26. Yao, Y.; Zhu, S.; Yue, S. A globally applicable, season-specific model for estimating the weighted mean temperature of the atmosphere. J. Geod. 2012, 86, 1125-1135. [CrossRef]

27. Yao, Y.; Hu, Y.; Yu, C.; Zhang, B.; Guo, J. An improved global zenith tropospheric delay model GZTD2 considering diurnal variations. Nonlinear Process. Geophys. 2016, 23, 127-136. [CrossRef]

28. Zhang, P.; Wu, J.; Sun, Z. Construction and Service of the National Geodetic Datum. Geomat. World 2018, 25, 39-41, 46.

29. Gan, W.; Li, Q.; Zhang, R.; Shi, H. Construction and Application of Tectonic and Environmental Observation Network of Mainland China. J. Eng. Stud. 2012, 4, 16-23.

30. Jin, S.; Park, P.-H.; Zhu, W. Micro-plate tectonics and kinematics in Northeast Asia inferred from a dense set of GPS observations. Earth Planet. Sci. Lett. 2007, 257, 486-496. [CrossRef]

31. Dach, R.; Lutz, S.; Walser, P.; Fridez, P. Bernese GNSS Software, version 5.2; Astronomical Institute, University of Bern: Bern, Switzerland, 2015.

32. Li, Z.; Wen, Y.; Zhang, P.; Liu, Y.; Zhang, Y. Joint Inversion of GPS, Leveling, and InSAR Data for The 2013 Lushan (China) Earthquake and Its Seismic Hazard Implications. Remote Sens. 2020, 12, 715. [CrossRef]

33. Saastamoinen, J. Contributions to the theory of atmospheric refraction. Bull. Géodésique 1973, 107, 13-34. [CrossRef]

34. Jin, S.; Luo, O. Variability and climatology of PWV from global 13-year GPS observations. IEEE Trans. Geosci. Remote Sens. 2009, $47,1918-1924$.

35. Liou, Y.-A.; Teng, Y.-T.; Van Hove, T.; Liljegren, J.C. Comparison of Precipitable Water Observations in the Near Tropics by GPS, Microwave Radiometer, and Radiosondes. J. Appl. Meteorol. 2001, 40, 5-15. [CrossRef]

36. Wang, J.; Zhang, L.; Dai, A. Global estimates of water-vapor-weighted mean temperature of the atmosphere for GPS applications. J. Geophys. Res. Atmos. 2005, 110. [CrossRef]

37. Guan, X.; Yang, L.; Zhang, Y.; Li, J. Spatial distribution, temporal variation, and transport characteristics of atmospheric water vapor over Central Asia and the arid region of China. Glob. Planet. Chang. 2019, 172, 159-178. [CrossRef]

38. Liu, Y.; Ding, Y. Analysis of the basic features of the onset of Asian summer monsoon. Acta Meteorol. Sin. 2007, 21, 511-526.

39. Zhao, Q.; Yang, P.; Yao, W.; Yao, Y. Hourly PWV Dataset Derived from GNSS Observations in China. Sensors 2020, $20,231$. [CrossRef] [PubMed]

40. Gui, K.; Che, H.; Chen, Q.; Zeng, Z.; Zheng, Y.; Long, Q.; Sun, T.; Liu, X.; Wang, Y.; Liao, T.; et al. Water vapor variation and the effect of aerosols in China. Atmos. Environ. 2017, 165, 322-335. [CrossRef]

41. Durre, I.; Williams, C.N.; And, X.Y.; Vose, R.S. Radiosonde-based trends in precipitable water over the Northern Hemisphere: An update. J. Geophys. Res. Atmos. 2009, 114. [CrossRef]

42. Wang, R. Characteristics of Water Vapor, Precipitation, Temperature and Humidity in Mainland China Based on IGRA and TRMM PR. Ph.D. Thesis, University of Science and Technology of China, Hefei, China, 2019.

43. Wong, M.S.; Jin, X.; Liu, Z.; Nichol, J.; Chan, P. Multi-sensors study of precipitable water vapour over mainland China. Int. J. Climatol. 2015, 35, 3146-3159. [CrossRef] 